\title{
Embedding Self-determination and Futures Planning within a Schoolwide Framework
}

\author{
Hank Bohanon \\ Loyola University Chicago, hbohano@luc.edu \\ Jose Castillo \\ University of South Florida, jmcastil@usf.edu \\ Morgan Afton \\ San Juan Diego Academy, morgan.c.afton@gmail.com
}

Follow this and additional works at: https://ecommons.luc.edu/education_facpubs

Part of the Education Commons

\section{Author Manuscript}

This is a pre-publication author manuscript of the final, published article.

\section{Recommended Citation}

Bohanon, H., Castillo, J., \& Afton, M. (2015). Embedding self-determination and futures planning within a schoolwide framework. Intervention in School and Clinic. 50 (4), 203-209. http://ecommons.luc.edu/ education_facpubs/16/

This Article is brought to you for free and open access by the Faculty Publications and Other Works by Department at Loyola eCommons. It has been accepted for inclusion in Education: School of Education Faculty Publications and Other Works by an authorized administrator of Loyola eCommons. For more information, please contact ecommons@luc.edu.

\section{(c) (i) $\ominus$}

This work is licensed under a Creative Commons Attribution-Noncommercial-No Derivative Works 3.0 License. (c) Hammill Institute on Disabilities 2014. 
Embedding Self-Determination and Futures Planning Within a Schoolwide Framework

\author{
Hank Bohanon, Ph. D. \\ Loyola University of Chicago \\ 820 N. Michigan Ave. \\ Chicago, IL 60611 \\ E-mail: hbohano@luc.edu \\ Jose Castillo, Ph. D. \\ University of South Florida \\ 4202 E. Fowler Avenue, EDU 105 \\ Tampa, FL 33620 \\ E-Mail: jmcastil@usf.edu \\ Morgan Afton, M. Ed. \\ San Juan Diego Academy \\ 16730 White Road \\ Bailey, MI 49303 \\ E-mail: morgan.c.afton@gmail.com
}

\begin{abstract}
Authors Note
The authors of this manuscript would like to thank Jennifer Rose for her work on the research related to this manuscript.

Please cite as

Bohanon, H., Castillo, J., \& Afton, M. (In Press). Embedding self-determination and futures planning within a schoolwide framework. Intervention in School and Clinic.
\end{abstract}




\begin{abstract}
The purpose of this paper is to illustrate the infusion of self-determination approaches (e.g., futures planning) within a schoolwide context. Unfortunately, some students are not explicitly instructed by school staff to address their plans for the future. This may be a result of school professionals' feelings of inadequacy to address skill sets outside of their specialization (e.g., content area, special education). By connecting self-determination practices with schoolwide initiatives (e.g., schoolwide positive behavior support, Common Core State Standards), educators in particular may be more willing to address these skills in their settings. This article provides an example of these types of connections with an actual case study of one student within an urban high school.

Keywords: self-determination, high schools, schoolwide, positive behavior support, multi-tiered supports
\end{abstract}




\section{Meet Sean}

Sean was attending high school in a large urban district and failing several classes, while struggling to find consistent shelter at night. At times, he would sleep on park

benches or in one of nine homes in which he lived over a three-year period. The recent death of his grandmother removed his one unconditional supporter. This loss was predated by the death of his father who was involved in a shooting when Sean was 11 years old. Sean had also been arrested for allegedly stealing another student's video game at school. Though hoping for a better future, he was not working proactively towards positive goals. His attendance at school was problematic due to frequent suspensions. He would become disruptive in class if the setting was chaotic, or if aroused by comments from other students. His mother expressed that she loved her son, but was very concerned about his behavior. She knew he was having difficulty in classes and sometimes not attending school. Although she would meet with teachers and staff as needed, she felt unable to encourage a change for the better. Fortunately, Sean was attending a school where the teaching staff and administrators piloted support programs to increase the success and self-determination of their students (see Note 1).

The purpose of this article is to describe a process for aligning self-determination and futures planning for students like Sean on a schoolwide level. As a result of this article, educators should be able to imagine a student like Sean in their class (e.g., students with academic and social support needs), and through this example develop ideas to encourage student success. The article will provide: (a) a description of supports that assist students who are working toward future goals using self-determination; (b) the connection between various schoolwide supports (e.g., multi-tiered interventions, proactive planning for school teams, preventing problem behaviors, responding to additional needs of students) and self- 
determination; and (c) an illustration of this connection. Sean's example will focus primarily on embedding self-determination within a schoolwide positive behavior support framework, as it connects with other schoolwide initiatives. Examples will be provided of the alignment of selfdetermination components encompassed in Sean's case with other schoolwide approaches including Common Core State Standards (CCSS; Gamm et al., 2012), response to intervention (RtI; Kurns \& Tilly, 2008), schoolwide positive behavior support (SWPBS; Horner, Sugai, \& Anderson, 2010), social and emotional learning (SEL; Durlak et al., 2011), and universal design for learning (UDL; Center for Applied Special Technology, 2013).

\section{Self-Determination}

Students require prerequisite skills for active planning for the future that include setting goals, self-advocacy, self-regulation, and self-monitoring (Mason, Field, \& Sawilowsky, 2004). These skills are a component of self-determination, defined as the ability to be self-regulated (e.g., self-evaluate), autonomous (e.g., set goals), self-realized (e.g., problem solve), and psychologically empowered (e.g., express wants and needs) (Wehmeyer, 1997). Individuals with disabilities who have learned and applied self-determination skills have been able to live more independently than those without them (Holburn, Jacobson, Schwartz, Flory, \& Vietze, 2004). For students with individualized education plans (IEPs), involvement in the development of their plan is a key component of self-determination.

While pre-teaching students about their involvement in their IEP is important (KochharBryant \& Greene, 2009), only $28 \%$ of students actually received instruction prior to their meetings (Mason et al., 2004). Additionally, while attendance in IEP meetings has increased in some cases, active participation is down (Mason et al., 2004). Most instruction on selfdetermination is informal and not related to personal planning. Many educators aspire to 
effectively teach self-determination skills (Mason et al., 2004). This desire could be nurtured into skill development if a stronger connection was made between academic achievement and goal-setting in core content areas (Mason et al., 2004). Approaching the teaching of selfdetermination within a schoolwide framework may be one way to embed self-determination within the core curriculum and still maintain high expectations for all students (Wagner \& Davis, 2006). This approach also would connect self-determination with other effective interventions embedded within schoolwide systems (e.g., progress monitoring, check in and check out, futures planning).

\section{Links Between Self-Determination, General Education, and Schoolwide Supports}

Teachers may be willing to address self-determination skills within the general curriculum. Embedding supports for individuals at risk of failure (including students with disabilities) within the general education curriculum can increase the likelihood that students will develop these skills in the Least Restrictive Environment (LRE). Further, bringing additional supports into the general education environment may also increase the achievement of all students, including those with disabilities (Sailor, Stowe, Rutherford Turnbull, \& KleinhammerTramill, 2007). Regrettably, many educators lack skills related to improving the schoolwide environment through enhancing their own classroom settings (e.g., classroom management; Wagner \& Davis, 2006), making the teaching of self-determination difficult. Connecting selfdetermination with schoolwide approaches may increase the likelihood that students will practice these skills throughout the day. Schoolwide supports may increase this possibility by connecting school staff to more training, addressing competing instructional priorities, overcoming limited access to resources, and addressing a lack of administrator support (Carter, Lane, Pierson, \& Stang, 2008). The following provides a brief explanation of some key schoolwide supports. 


\section{Schoolwide Supports}

Each of the schoolwide initiatives that follow have similarities and differences among them. All provide useful connections for integrating self-determination into the core curriculum at some level.

Common Core State Standards. As previously stated, another schoolwide initiative is CCSS (Gamm et al., 2012), which represents a challenging set of curriculum standards that focus deeply on core content knowledge and skills, problem-solving, and critical thinking. The CCSS includes several literacy learning standards that address skills related to self-determination by expecting students to express themselves effectively (CCSS.ELA-Literacy.SL.9-10.1) and develop and evaluate a plan (CCSS.ELA-Literacy.WHST.9-10.5). For some students, selfdetermination planning may be the instruction and support that is needed to facilitate mastery of the skills evident in the standards. Self-determination curriculum materials and instruction can be incorporated into general education instruction to promote connections across settings.

Response to intervention. RtI is another schoolwide model that includes: (a) providing high quality interventions and instruction across multiple tiers, and (b) the use of data to identify the needs of students and to monitor their progress (Fletcher \& Vaughn, 2009). RtI often includes the use of a problem-solving process that scaffolds educators' use of data to make important educational decisions (Batsche et al., 2005). An emphasis within this model is the explicit teaching of skills related to identified skill deficits (Kurns \& Tilly, 2008). Other issues that impact student learning (e.g., instruction, curriculum, learning environment) also are identified and addressed through the problem-solving process. The success of self-determination for students may be more frequently monitored in an environment where summative, formative, and diagnostic data are part of the instructional culture. When the default response of staff 
becomes explicitly teaching to ameliorate skills deficits, staff may begin to see addressing selfdetermination needs as being within their skill set.

Social and emotional learning. SEL, a schoolwide approach to developing students' social and emotional skills, may also facilitate the use of self-determination planning. SEL has been defined as "a process for helping children and even adults develop the fundamental skills for life effectiveness. SEL teaches the skills...[people]... need to handle... relationships, and ...work, effectively and ethically" (Collaborative for Academic, Social, and Emotional Learning [CASEL], 2007, p. 1). If schools are addressing SEL, they may already be teaching social awareness, self-awareness, self-management, responsible decision making, and relationship skills (CASEL, 2003) through sequenced, active, focused and explicit instruction (Durlak et al., 2011). Once again, students engaging in self-determination planning would be exposed to these concepts, allowing educators facilitating planning efforts to use similar language and concepts and to better coordinate with the students' general education teachers.

Universal Design for Learning. Schools also may be implementing UDL. The framework for UDL includes embedding scaffolding around learning barriers. These supports are provided by presenting content and information in multiple ways, engaging students in the content by stimulating interest and motivation, and allowing for differentiation when students express what they know. Within UDL, curriculum materials, instructional delivery, and technology are designed to enhance access to content (Center for Applied Special Technology, 2013) to help all students meet performance standards. For example, schools may provide flexible means of engagement and expression by increasing student choice making regarding topics for assignments. UDL provides individuals engaged in self-determination planning the 
opportunity to make choices regarding how to accomplish the goals and tasks outlined in their plans.

Schoolwide positive behavior support. Another approach to creating effective schoolwide environments is SWPBS. The SWPBS approach is an evidenced-based practice that includes universal, secondary, and tertiary supports (Horner et al., 2010). Because all students are taught expectations for behavior, and additional supports are available to students identified as at-risk, self-determination instruction can be embedded into existing practices. For example, Sean's school had universal (e.g., teaching expectations) and some secondary level supports in place and was beginning to implement tertiary supports that incorporated the development of self-determination through person-centered planning (Malloy, Sundar, Hagner, Pierias, \& Viet, 2010). Sean's experience was primarily embedded within a SWPBS context. Connections with other schoolwide supports (SEL, UDL) will be described in detail. Teachers and staff supporting students engaged in self-determination planning can use these approaches to teach students to identify resources available, to develop a plan that they are willing and able to implement, and to seek out support in implementing and evaluating the success of their plans. Sean's example illustrates how intensive supports can be aligned with these initiatives.

\section{Example of Futures Planning within Schoolwide Supports}

At the time of the study, Sean was a high school student attending a diverse urban district with over 400,000 students. Sean's school had been implementing SWPBS for several years, had reached full implementation of SWPBS, and had significant reductions in office discipline referrals (Bohanon \& Wu., 2013). While not perfect, the overall climate and systems of support were improving in this setting. The schoolwide expectations for this school stated that students and staff should be Productive, Appropriate, Respectful, and Responsible. 


\section{Identifying a Student With Needs}

Sean was selected by his school counselors as someone who required intervention beyond universal supports alone. His problem behaviors included being disruptive in class, frequent absences, and failing courses. He was receiving some secondary level supports related to instruction. The development and support of teams across tiers is a common practice within RtI, SWPBIS, SEL, and other multi-tiered supports.

\section{Conducting the Assessment}

In preparation, the team and university based external coaches conducted a functional behavior assessment (FBA) (Chandler \& Dahlquist, 2010) and completed reading and math portions of the Brigance Assessment to determine Sean's academic needs. The use of academic data related to literacy was another connection with CCSS and RtI. The Functional Assessment Checklist for Teachers and Staff (FACTS; 2007) was completed as an interview with the team to develop an initial hypotheses of Sean's behavior.

Behavioral rating (Christ, Riley-Tillman, Chafouleas, \& Jaffery, 2011) data were gathered to inform the team about Sean's academic, behavior, and social indicators across settings. To obtain these data, the team completed a version of the Home, School, Community Tool (2006) (i.e., measure of quality of life) to gain knowledge of his needs and strengths across settings related to quality of life. The Education Information Tool (2007) (i.e., measure of student performance) also was used to gain information about his current performance across settings. The data collected from these assessments were valuable in developing an understanding of Sean's needs from multiple perspectives. The use of these types of data also is common practice within SWPBS, RtI, and other multi-tiered models of supports. 
The hypothesis of his FBA based on the aforementioned data indicated that Sean would not complete his work and would become disruptive when presented with unstructured, highly frustrating, and group related work in math class in order to escape the academic task and to obtain adult attention. Based on the Brigance data, Sean's skill set in math was below the skill level required in his math course. Disruptive behavior included talking out in class while others were working or yelling at other students. Developing a working hypothesis regarding a performance problem is a key practice of both RtI and SWPBIS. These target behaviors were related to CCSS, which will be described (CCSS.ELA-Literacy.SL.9-10.1). Due to skill deficits in math, lack of a consistent home environment, and lack of adult attention outside of school (related to RtI, SEL, and SWPBIS), escaping tasks and accessing adult attention at school may have been highly reinforcing for his problem behavior. The checklists mentioned were available to track his progress as a repeated measure of growth (Christ et al., 2011) related to his target behaviors (e.g., decreased disruption, increased engagement, academic success in math), a component of CCSS, RtI, and SWPBS.

\section{Creating a Plan}

A behavior intervention plan (BIP) was developed with the assistance of the tertiary team, which included key teachers for Sean, a school counselor, and two external coaches from the local university. The BIP includes supports to address setting events (e.g., factors related to student quality of life), preventing problem behavior, teaching new skills to replace problem behavior, and consequence strategies to support the new behaviors. Recommended setting event interventions included: (a) remediating academic deficits, (b) teaching conflict management strategies to develop long terms skills for interacting with peers, (c) developing a futures plan to address personal needs (e.g., housing, positive connections with peers), and (d) developing a 
checklist for morning and evening routines to help with attendance issues (e.g., when to go to bed, preparing for the day). The latter two strategies were related to explicitly teaching skills, a common practice of RtI, related to SEL outcomes. Prevention strategies included: (a) providing Sean with a choice of groups of students with whom he could work to increase his selfdetermination and decrease his contact with students who might trigger his problem behavior, and (b) teaching the entire class how to enter the room based on the schoolwide expectation of being appropriate to decrease the level of collective disruptive behavior (i.e., "chaos") that triggered Sean's disruptive behavior. Choice making is also a component of UDL which allows for flexible means of engaging in the content (e.g., choosing with whom to work). The direct teaching of classwide expectations was based on both RtI and SWPBS practices. Replacement behaviors for Sean included teaching him to: (a) ask for breaks and assistance when necessary at times when he felt frustrated with academic work though verbal requests, and (b) receive feedback from staff and self-monitor his application of these new skills using a daily check- in and check- out form. Both of these interventions were related to SEL skills for self-evaluation and self-monitoring and SWPBS interventions. Teaching Sean to express himself appropriately and monitor his plan was related to literacy CCSS and RtI practices for monitoring. The consequence strategy for Sean involved allowing him to check in and check out with someone at the beginning and end of the day to provide feedback about his daily performance. As seen in explanation of setting event interventions, there were several quality of life needs that could be addressed through a person-centered futures plan.

A university faculty member and graduate student (serving as external coaches) conducted the futures plan with Sean. The coaches followed a questioning route with Sean outlined in the Rehabilitation for Empowerment, Natural Supports, Education, and Work 
(RENEW) model (Malloy, Couture, \& Drake, 2012) (see Table 1). These prompts were designed to develop a person-centered picture of the students past, present, and future. An adapted version of the Illinois Wraparound Integrity Tool (2008) was used to track the level of implementation of intensive support over time. While not all components were in place, the tool highlighted the areas where the team would need to address systems of support in order to further Sean's plan.

$<$ Insert Table 1 here>

Sean and the two external coaches developed a plan of action (Espiner \& Guild, 2012) to guide his next steps for the team. His key goals were to obtain a job, own a car, have his own apartment, be a rap artist, and to be a manager of a business. His long term goals were contingent upon more immediate short term goals. These short term goals included setting aside money for a bus pass, talking with a neighbor who worked at a potential job site, obtaining and completing job applications, practicing interview skills with a family member, reloading his cell phone minutes for job related calls, setting a regular sleep schedule, and connecting with the school counselor to identify alumni who were working in the music industry. These steps addressed some of the setting events from his behavior plan in that he was working towards addressing his morning routine and putting himself in more frequent contact with positive adult attention. These goals also connected with schoolwide supports. His work on goal setting was related to SEL and self-determination based components. The supports that connected with his family also were related to SEL and SWPBS (e.g., wrap around) approaches. Further, his ability to effectively express his point of view to others was related to CCSS of literacy (CCSS.ELALiteracy.SL.9-10.1). Finally, Sean was directly taught replacement skills within an environment that was more likely to recognize these traits (related to SWPBIS and RtI), the development of 
his plan was supported by teams (RtI, SWPBIS, and SEL components), the skills were based on the identified problems (RtI, SWPBIS), and included high levels of choice for Sean (UDL). Figure 1 provides a visual example of the connections between self-determination and schoolwide supports as they related to Sean's examples. $<$ Insert Figure 1 here $>$

\section{Future Directions}

As can be seen from the description above, the team was able to develop a function-based intervention plan for Sean. These types of plans are related to schoolwide approaches (SWPBIS) and may be more effective for students (Gettinger \& Stoiber, 2006). Additionally, the team was able to incorporate function-based supports with self-determination skills development (Malloy et al., 2010), which connected Sean's BIP with SEL related skills. The team did appear to readily adapt to the use of data at these team meetings, a key component of all schoolwide initiatives. This staff had created a culture where data were reviewed on a regular basis as a part of a schoolwide approach, in this case SWPBS. This is similar to other projects that have found more success for more intensive supports within school settings that implement SWPBS with higher fidelity (Eber et al., 2009).

Some of the concerns for the team included a lack of consistency when working with Sean. Somehow Sean's teachers interpreted that his individualized plan meant that they did not need to hold him accountable for attendance. This, too, could be associated with the lower levels of individualized supports in place. Further, some of the team members became easily discouraged by some of the struggles that Sean experienced even after the plan was in place. This, too, may be due to the lack of schoolwide application of more individualized supports. Further training to both increase implementation and improve the ability for teachers to maintain 
prolonged engagement, should emphasize that interventions take time (there are really no failures if you know how to make an adjustment), and tertiary supports do not include a free pass from consistent consequences.

As a response to some of the concerns around implementation, the team agreed to meet again to discuss with Sean's mother issues about attendance, develop a better sense of the quality of life factors around Sean's attendance needs, and review his person-centered plan to discuss his goals related to his dreams. While not a perfect plan or outcome, the process did create an experience to help develop key supports for Sean based on his needs, and it helped him and the staff to develop a plan that would address his future hopes and dreams. Sean also may have benefited from a more formalized mentoring program (DuBois \& Karcher, 2005). While he had been connected with a mentor, he frequently did not attend his meetings. A more formal structure may have addressed this issue.

This example is one of the first examples for incorporating self-determination within SWPBS in an urban high school setting. Urban high school staff may face unique challenges to teaching self-determination to their students due to issues such as gang involvement and violence. Further alignment within schoolwide initiatives (e.g., UDL, SEL) would increase the likelihood that these teachers would be willing to directly teach self-determination skills. This alignment perhaps would connect self-determination with supports instructors are already addressing, decreasing the chance this work would be interpreted as "one more thing" to do.

\section{Concluding Thoughts}

The hope for Sean's case is to provide useful examples for educators. More work is needed to ensure that students who are most at risk of failure have access to supports to ensure their success. In order to prevent school staff from being overwhelmed by requests to implement 
multiple initiatives, they must be encouraged to see the logical connections between them. Further, by aligning interventions and professional responsibilities by tasks rather than programs and specializations alone (Alin, Maunula, Taylor, \& Smeds, 2013), it may be possible to reach higher levels of effectiveness and efficiency in school settings. Each of the systems described encourages the proactive behavior of adults to positively influence student outcomes. They also encourage ensuring interventions are implemented with a high degree of fidelity. This also will deter staff from saying interventions did not work when approaches were not implemented correctly. Thinking about integrating schoolwide approaches and self-determination may be one way to address the needs of students and to encourage the adoption of self-determined related practices by all teachers and staff.

Note 1. The data presented in this case example are taken from an actual research study in a high school. Only the names are changed to pseudonyms to protect the confidentiality of the participants. 


\section{References}

Alin, P., Maunula, A. O., Taylor, J. E., \& Smeds, R. (2013). Aligning misaligned systemic innovations: Probing inter $\square$ firm effects development in project networks. Project Management Journal, 44(1), 77-93. doi: 10.1002/pmj.21316

Batsche, G. M., Elliot, J., Graden, J. L., Grimes, J., Kovaleski, J. F., Prasse, D., Reschly, D. J., Schrag, J., Tilly, W. D. (2005). Response to intervention: Policy considerations and implementation. Alexandria, VA: National Association of State Directors of Special Education, Inc.

Carter, E., Lane, K., Pierson, M., \& Stang, K. (2008). Promoting self-determination for transition-age youth: Views of high school general and special educators. Exceptional Children, 75(1), 55-70. doi: 1548558211

Center for Applied Special Technology (2013). About UDL. Retrieved from http://www.cast.org/udl/index.html

Chandler, L. K., \& Dahlquist, C. M. (2010). Functional assessment: Strategies to prevent and remediate challenging behaviors in school settings (3rd ed.). Upper Saddle, NY: Pearson.

Christ, T. J., Riley-Tillman, T. C., Chafouleas, S., \& Jaffery, R. (2011). Direct behavior rating: An evaluation of alternate definitions to assess classroom behaviors. School Pschology Review, 40(2), 181-199. Retrieved from: http://www. nasponline.org

Collaborative for Academic, Social, and Emotional Learning (2003). Safe and sound: An educational leader's guide to evidence-based social and emotional learning (SEL) programs. Retireved from the Collaborative for Academic, Social, and Emotional Learning website: http://casel.org/wp-content/uploads/1A_Safe_Sound-rev-2.pdf 
Collaborative for Academic, Social, and Emotional Learning. (2007). Implementation guidance. Retireved from the Pathways to Reslience website: http://www.pathwaystoresilience.org/wp-content/uploads/2011/09/CASEL-Backgroundon-Social-and-Emotional-Learning.pdf

Education Information Tool. (2007). Retrieved from http://pbis.org/evaluation/evaluation_tools.aspx

Eber, L., Phillips, D., Upreti, G., Hyde, K., Lewandowski, H., \& Rose, J. (2009). Illinois positive behavioral interventions \& supports (PBIS) network 2008-09 progress report. La Grange Park, IL.

Espiner, D., \& Guild, D. (2012). Capturing what matters most. Teaching Exceptional Children, 44(5), 56-67. Retrieved from http://www.cec.sped.org

Fletcher, J. M., \& Vaughn, S. (2009). Response to intervention: Preventing and remediating academic difficulties. Child Development Perspectives, 3(1), 30-37. doi: 10.1111/j.17508606.2008.00072.x

Functional Assessment Checklist for Teachers and Staff. (2007). Retrieved from http://pbis.org/evaluation/evaluation_tools.aspx

Gamm, S., Elliott, J., Halbert, J. W., Price-Baugh, R., Hall, R., Walston, D., . . Casserly, M. (2012). Common Core State Standards and diverse urban students: Using multi-tiered systems of support. Retireved from the Council for Great City Schools website: http://www.cgcs.org/cms/lib/DC00001581/Centricity/Domain/87/77-Achievement\%20Task\%20Force--RTI\%20White\%20Paper-Final.pdf 
Gettinger, M., \& Stoiber, K. C. (2006). Functional assessment, collaboration, and evidence-based treatment: Analysis of a team approach for addressing challenging behaviors in young children. Journal of School Psychology, 44(3), 231-252. doi: 10.1016/j.jsp.2006.03.001

Holburn, S., Jacobson, J. W., Schwartz, A. A., Flory, M. J., \& Vietze, P. M. (2004). The Willowbrook futures project: A longitudinal analysis of person-centered planning. American Journal on Mental Retardation, 109(1), 63-76. Retrieved from http://www.montclair.edu/profilepages/media/1602/user/Willowbrook_longitud.pdf

Home, School, Community Tool. (2006). Retrieved from http://pbis.org/evaluation/evaluation_tools.aspx

Horner, R. H., Sugai, G., \& Anderson, C. M. (2010). Examining the evidence base for schoolwide positive behavior support. Focus on Exceptional Children, 42(8), 1-14. Retrieved form http://www.lovepublishing.com/catalog/focus_on_exceptional_children_31.html

Illinois Wraparound Integrity Tool. (2008). Retrieved from http://pbis.org/evaluation/evaluation_tools.aspx

Kochhar-Bryant, C. A., \& Greene, G. (2009). Pathways to successful transition for youth with disabilities. Upper Saddle River, N.J.: Pearson Education Inc.

Kurns, S., \& Tilly, W. D. (2008). Response to intervention blueprints: School building level edition. 78. http://www.nasdse.org/Portals/0/SCHOOL.pdf

Malloy, J. M., Sundar, V., Hagner, D., Pierias, L., \& Viet, T. (2010). The Efficacy of the renew model: Individualized school-to-career services for youth at risk of school dropout. Journal of At-Risk Issues, 15(2), 17-24. Retrieved from http://eric.ed.gov/?id=EJ942876 
Mason, C., Field, S., \& Sawilowsky, S. (2004). Implementation of self-determination activities and student participation in IEPs. Exceptional Children, 70(4), 441. Retrieved from http://www.cec.sped.org

Sailor, W., Stowe, M. J., Rutherford Turnbull, H., \& Kleinhammer-Tramill, P. J. (2007). A case for adding a social-behavioral standard to standards-based education with schoolwide positive behavior support as its basis. Remedial and Special Education, 28(6), 366-376. doi: $10.1177 / 07419325070280060601$

Wagner, M., \& Davis, M. A. (2006). How are we preparing students with emotional disturbances for the transition to young adulthood? Findings from the National Longitudinal Transition Study--2. Journal of Emotional \& Behavioral Disorders, 14(2), 86-98. doi: $10.1177 / 10634266060140020501$

Wehmeyer, M. (1997). Self-determination and positive adult outcomes: A follow-up study of youth with mental retardation or learning disabilities. Exceptional Children, 63(2), 245255. http://www.cec.sped.org 
Table 1

Sample Questions for Guiding Your Plan

\section{Mapping Your Future}

These sample questions will help guide you and your team as you develop your maps for your future.

Key Questions

What is your history/story?

Who are you today?

What are your strengths and accomplishments?

Who are the people and resources in your life?

What are the experiences that do/do not work for you?

What are your dreams?

What are your fears, concerns, and barriers?

What are your goals?

\section{Prompts for facilitation}

What have been some of the toughest/best things that have happened to you?

Describe how things are going for you at home and school.

What are you most proud in terms of your accomplishments?

Who are the people you do/do not you turn to for help?

How do you learn best?

What do you hope will happen in five years?

What has stopped your goals in the past?

What has to happen in the next one to two years to help you reach your dream?

Note: See RENEW Youth Portfolio (Malloy, Couture, \& Drake, 2012)

http://www.iodbookstore.org/products/RENEW-Youth-Portfolio.html to access this guide. 
Figure 1. Embedding Self-Determination Within Tiers of Support

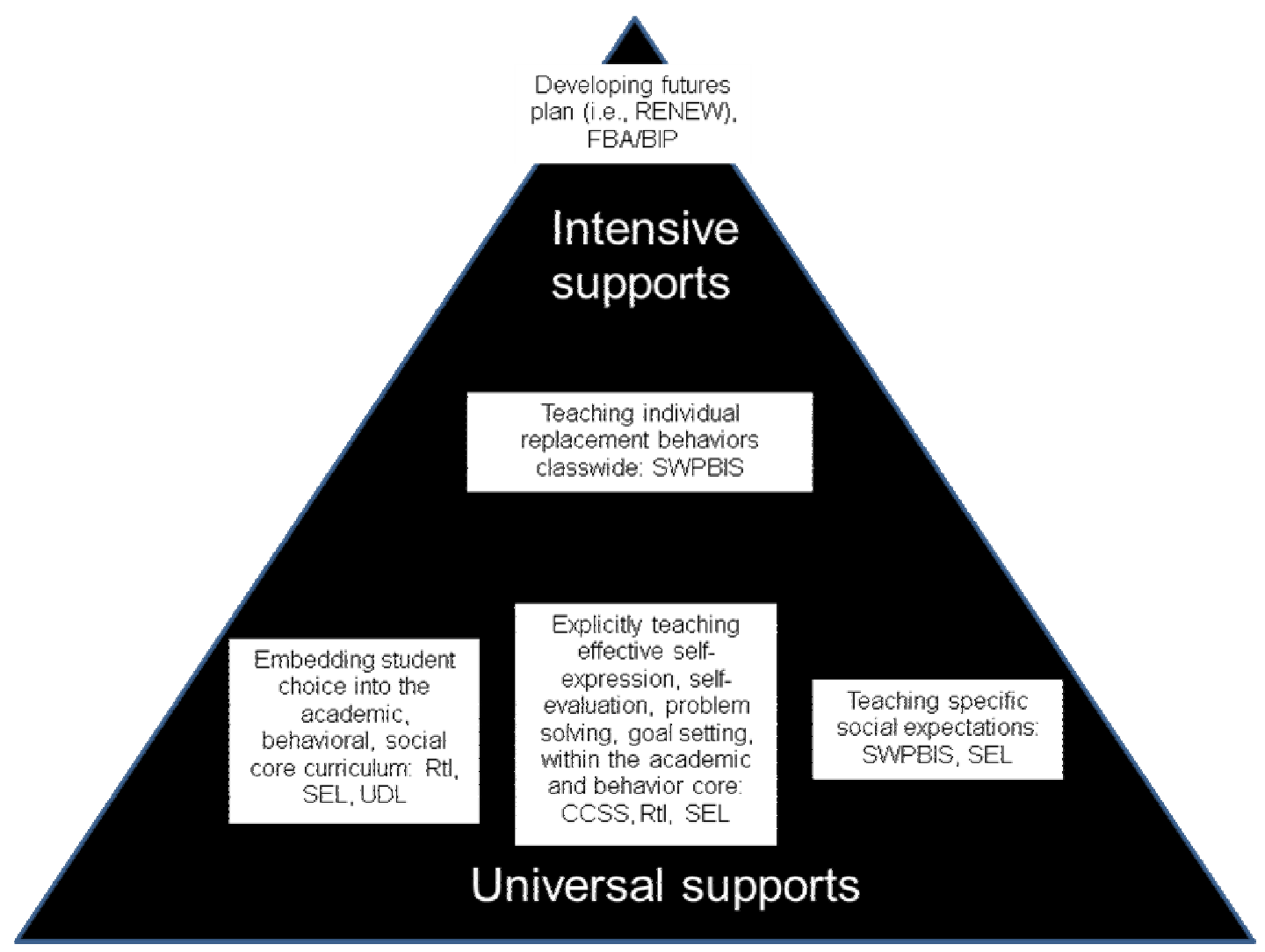

Figure 1. Example of one student's BSP and futures plans with alignment to schoolwide supports. 